\title{
Information Communication and Technology (ICT) and the Challenges of Ideation in Graphic Design: An Activity Theory Focus
}

\author{
Edward Appiah \\ Faculty of Informatics and Design \\ Cape Peninsula University of Technology \\ Cape Town, South Africa
}

\author{
Johannes Cronje \\ Faculty of Informatics and Design \\ Cape Peninsula University of Technology \\ 2nd Cape Town, South Africa
}

\begin{abstract}
The introduction of technology into graphic design education has resulted in some challenges within the pedagogy of ideation. In ideation, - generating, developing, and testing ideas leading to solutions - influences of technology are creating new possibilities for students to conceive ideas differently from the traditional methods. Using activity theory as a lens, the paper discusses the 'disturbances' in the ideation process of graphic design with ICT, especially within large class in a developing country. It concludes with a call for a review of pedagogical issues of ideation with a conviction that such disturbances can be overcome with the right pedagogy, with ICT as a support in the ideation process. Whatever our scepticism about ICT, there is some important aspects that can only be addressed if we adopt some of the new digital technologies, by modifying the current pedagogy.
\end{abstract}

\section{General Terms}

Graphic design, human-computer interactions, Innovation Education (IE)

\section{Keywords}

Design processes, graphic design, ideation, pedagogy.

\section{INTRODUCTION}

The introduction of technology into graphic design education has resulted in some challenges within the pedagogy, as it requires relearning, training and upgrading. One of the critical areas in design education that has attracted much attention as a result of ICT introduction is the issue of ideation [1-3]. According to Yeoh[4], while teachers are caught in the conundrum of teaching a generation of technologically literate students, especially in the issue of ideation, 'they must also allow them the opportunities to explore their own strengths and weaknesses with a piece of so called anti-creativity equipment' [4]. If such opportunities are going to be meaningful, it requires that educators also take another look at the pedagogy that informs ideation. This paper, which is part of on-going research into how ICT is impacting on the teaching and learning of ideation, is in line with how the ideation pedagogy should be a focus in design research. Studies into how students are using ICT in their ideation process will help educators re-look at the pedagogy and possibly, make some informed decisions as to current educational paradigms. Bender [5] postulates that, as technology becomes more transparent in the learning process and offerings of online courses continue to rise, knowing how technology affects teaching and learning is imperative for educators. What this also means is that research into areas of educational use of ICT such as pedagogy, identity and electronic learning portfolios (e-portfolios) will have to be increased and, in this context, ICT and the ideation process. For this study, the focus was to explore the integration of ICT in the design process that includes the process of ideation, in the broader context of its "effective link between purpose, people, and pedagogy inside the institution" [6].

Design education has undergone various changes 'mainly as a result of developments in information and communication technology (ICT), the commercialization and globalization of education, social changes and the pursuit of quality' [7]. The indispensability of information and communication technologies has led to graphic design educators supporting their teaching and learning with ICT, one way or the other. As a result of this, new ideas and possibilities in design education and its practices, such as online studio as a support for learning and teaching [8], [9] and blended learning, which involves both traditional face-to-face instruction and asynchronous and/or synchronous communication via the Internet [10] have all come up as innovations in the design education. Moreover, new courses are also being designed in response to growing needs of ICT in design education [5] [11]. Educators need to find answers to the following questions: How do educators regulate the issue of ideation in graphic design with ICT? What are the perceptions of ICT by design students in the current graphic design pedagogy? What are the purposes of ICT in the modern studio, and how do they feature in the ideation process?

\section{LITERATURE REVIEW}

\subsection{Ideation}

Ideation is 'seen as a matter of generation, developing and communicating ideas, where 'idea' is understood as a basic element of thought that can be either visual, concrete or abstract' [1]. It is a sense-making activity that helps us to 
knock around our half-formed ideas in the search for greater sense that shapes our design solution [12]. Brown [13] also sees ideation as 'the process of generating, developing, and testing ideas that may lead to solutions' [13]. Ideation involves the mind acting in consonant with the environment or tools for which design sometimes involves subconsciousness. Ideation can also be seen as an ability to conceive a plan for a particular purpose or effect [14]. Within the ideation process, one engages with the mind and tools in the process of brainstorming, organising, sketching and drawing, when thinking and imagining with the view of creating ideas for implementation [12]. This process is best described metaphorically as a system of spaces rather than predefined series of orderly steps [13]. In his three-phase design-thinking model, Brown [13] put ideation in between "inspiration" and "implementation" loops, and believes that the process will loop back more than once as ideas are refined and new directions are taken (Figure 1). For our study, ideation involves the processes of thumbnail sketches, brainstorming and organisation that result in the actualization of a desired concept for implementation as approved by the lecturer/educator. Such concept will have to reveal the layout of text/fonts and images that will later be refined by students

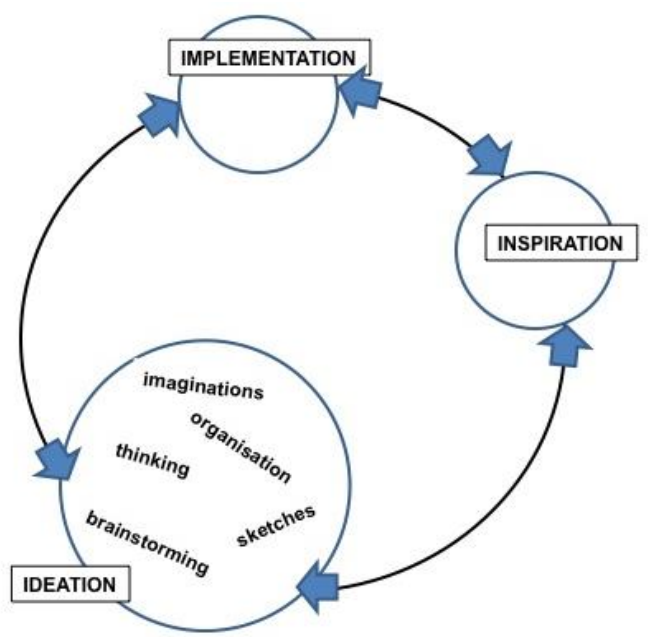

adding appropriate images.

\section{Figure 1: A three-phase design-thinking model for design process [13].}

Design processes adopted for creative work in design are derived from "Ideation" models [15], [16]. More importantly, creative thinking tools such as brainstorming enable one to have many ideas to choose from [15]. Designers have to undergo through these brainstorming sections to arrive at the creative work by doing thumbnail sketches and some preliminary drawings, also referred to as idea development. Schenk [17] sees drawing as a vehicle for creative interchange in group sessions in which the designers share and stimulate ideas. Many designers use drawing to develop their visual literacy and fund of 'stored analogy' to support creative behaviour.
Traditionally, ideation is viewed as a paper-based activity but as ICT enters the scene of teaching and learning in graphic design, there seem to be some 'disturbances' in the practices as students veer into the use of ICT in their ideation process. This situation becomes more problematic because there seems to be no pedagogy for ICT integration. The result therefore is a picture of distortion in the ideation steps as far as the pedagogy of idea development is concern. In the traditional principles of design, idea development calls for step by step approach of sketches that depicts the stages of evolving and recording of concepts and ideas on paper, leading to capturing of final idea to the solution as required by the brief. However, students seem to 'capture' ideas differently, creating a situation that makes one wonder if such ideas were preconceived before developing them with ICT, as interacting with technology has become 'natural' to them. Anecdotal evidence indicates that educators see these tensions as disturbing issues and a deviation from the learning outcomes of the pedagogy of ideation in graphic design. Ideation in graphic design is geared towards finding a solution, not only to studio work, but also to real-life challenges as far as design is concerned. Indeed, it is an essential part of the design process, both in education and practice [1]. The Bauhaus principles, which call for the learner to open up to issues solely from the master, might not be the most appropriate educational paradigm when it comes to ICT integration.

Schenk [18] admits that even though computer-technology can provide a viable substitute for many of the skill-based drawings, they do not support early ideation [18]. Influences of technology are creating new possibilities for students to conceive ideas different from those generated by the traditional methods of drawing and sketching. Design educators must begin to look at how current graphic design pedagogy, based on the principles of the Bauhaus concept, engage with the current practices of ideation using ICT. Understanding the phenomena that engage students and educators in the use of ICT within the process of ideation in graphic design will help educators admit the role of ICT in ideation, thereby frame an appropriate pedagogy for ideation with ICT. Using activity theory as a lens, this study observed activities and documents, which displayed the fact that ICT is changing the issues with ideation. Much therefore needs to be done by educators to correct and regulate the disturbances and tensions that characterise the issue of ideation in graphic design with ICT integration by students, by adopting innovation in education and pedagogy that seeks to accept ICT with ideation.

\subsection{Framework for graphic design}

In his 'study on the influences of computer usage on idea formation in graphic design students'; Yeoh [14] discusses three relevant theoretical fields that framed his study. These are market-driven frameworks, graphic design processes and theories, and models of creativity.

Within the graphic design process framework, Yeoh places great emphasis on visual exploration in ideation by designers 
since that is considered to be an essential part of the design process. He also sees sketching in ideation as "that which materializes the content of an image and is importantly linked to the formation of images" [14]. Through sketching, ideation can be reinterpreted and this creates many opportunities for exploration and also an important tool for understanding and discovering design paradigms.

Design paradigms can act as powerful tools for creating new designs since they encourage interactivity.... By exploring new paradigms and applying learned paradigms, designers learn what works and what does not [1].

In theories and models of creativity, one describes how creativity is intertwined with the design process and it becomes important to describe the concepts, approaches, phases, and methods rather than creativity all by itself. The concentration should be more on graphic design methods, technology associated with the field, and design pedagogical perspectives. All these perspectives add important dimensions to the concept and thus create some complexities of knowledge in graphic design. These complexities are part of graphic design [19].

\subsection{Framework for design-based education}

Sagun et. al [20] make a case for a framework for web-based education, which is applicable to technology-based design studio, seeing that design education involves lecture and studio teaching to engage students with design knowledge, skills and practice [20]. The framework considers pedagogical, ideological and epistemological levels relating to design education, which include studio approach, toolsmediated systems and outcome-based results.

The first step of the framework involves looking at the objectives (why): the methodology and management issues and the question of 'why' a technological-based system is preferred to traditional design system. The next step involves practical issues: can technological-based education be practiced in either as a support to the existing traditional teaching methods or a complete replacement of the existing method. It also looks at the major implications of the design and delivery of technology-based education and of the study requirements of the learner. Tools ranging from simple programmes to large expensive software packages can be used in a technological-based course.

In a pragmatist, but interpretive quadrant that seek to explore pedagogical issues, our aim was to inquire why ICT is being engaged in the ideation phase and how it is imparting on graphic design. Using activity theory as a lens, the study looks at complexities that have evolved since the introduction of ICT into the teaching and learning of ideation in graphic design.

\subsection{Activity theory as a framework for graphic design}

A framework of activity theory (AT) was used as a theoretical lens to analyse ideation in graphic design. The theory explores, through observation and interviews, how students use of tools-mediated systems in their ideation process for an outcome. According to Tan and Melles [19] using activity theory in such an exploratory study helps to understand the complex and intriguing aspect in the field of ideation. The aim is not to answer the question of why but how the introduction of ICT in graphic design education is affecting the teaching and learning process of ideation.

As a model for the analysis of tool-mediated professional and everyday practice, activity theory offers a potential framework for such an analysis ([19]. Tan and Melles [19] made a case for activity theory in graphic design research with the following statement:

In comparison to other frameworks..., activity theory appeared to have certain advantages for analysing situated graphic design practices. While protocol analysis and laboratory studies are commonly used for research into graphic design, activity theory as a framework provides a model that is appropriately oriented towards qualitatively focused studies of real-world practice, where the concern is to achieve depth of data rather than large sample sizes [19]

\subsubsection{Philosophy of activity theory}

People meet social needs by working and learning over time to achieve particular goals or to act on particular motives. To facilitate their activities, they also develop systems and use tools. These tools include pencils and sketchbooks, ICT and ideas. As people refine their tools and add new ones to solve problems more effectively, the activities they perform using those tools can change. As the activities change, they use their tools differently and modify the tools to meet their changing needs.

Justifying the use of Activity Theory in their research into graphic design, Tan and Melles [19] also considered its applicability to the complexities of the observed world as grounds in the analyst account [19]. The complexities of graphic design education stem from the use of tools and strategies; no matter how 'unrefined' they may be, to reach a defined objective in the contemporary world of design. It involves a range of personal decision-making, design and creative activities, together with the use of preferred tools and strategies [19].

According to Brown [13] some of the complexities that involve the process of idea development in solving design problems arise because, design is not just coming out with a product, but also ideas, services and systems, focusing more on the processes rather than the product. Activity theory takes into account the complexities of the observed world in graphic 
design [19], and has been used in analysing technology in higher education [21], designing constructivist learning environment [22] and conceptual designing in graphic design [19]. While we are engaged in the discussions of what students are doing in their ideation process, it is also important to explore their intentions and the circumstances that ascribe the ideation activity within the larger community of the design profession.

Tan and Melles [19], in using activity theory to investigate the problem-solving process of graphic design practice, were of the view that, activity theory provided "a model that is appropriately oriented towards qualitatively focused studies of real-world practice, where the concern is to achieve depth of data rather than large sample sizes" [19]. However, in the reality of the learners' studio, students will have to make informed decisions after briefs, as to know and understand what methods of ideas that will make meaningful, the issue of ideation for reaching their outcomes. In ideation, the brainstorming process can include a myriad of available tools, images and sketches that sometimes might not require definite steps of progressions. Activity theory borders on actions undertaken by subjects while interacting with tools and their environment [23].

A 'hidden' concept of activity theory is the changing of circumstance and human activity called revolutionary practice ([24] captured by Karl Marx, whose works echoed some of the philosophical roots of activity theory. Human beings are bound to change in the way they do things as a result of environmental and societal influences and other interactions. Such changes do occur in practice either through consciousness or unconsciousness. Issroff and Scanlon [21] believe that activities cannot be isolated as units, since activity systems are almost always in flux as they are in the process of working through contradictions [21].

To further understand the theory and its relationship to the ideation process, there is the need to discuss the issue of transformation as one philosophy within activity theory. Within the activity system dwells the process of the subject trying to meet a 'distant' object. Such directional activity reflects a transformation of ideas and thoughts. In [19] case, two levels of activity were observed: iterative activity patterns during periods of creativity and linear activity patterns observed during routine processes. All these were the result of mediated tools that were used to reach their objectives and outcomes.

Activity theory was employed to explore the tensions, disturbances and experiences created by everyday activities of the students and the lecturer of graphic design as they interact with ICT in their ideation process. This is a complex situation since the teaching of the ideation process was conceived on a non-ICT platform, but is currently being grappled with the use of ICT. There is therefore the need to first establish whether ICT is creating such tensions and look at the implications of such tensions on current pedagogical imbalance.

In this study, the subject will be a group of design learners/students (group/individuals), whose objective is to produce creative designs (videos/photographs/drawings/animations) that will communicate ideas or message according to briefs (outcome). The mediating tool or artefact is the ICT tools, made up of computers/world wide web/cameras/videos, which have been dominating graphic design profession currently. The main activity of exploration is the issue of ideation, which is fundamental to design process. Ideation in this context will include (but not limited to) 'the process of generating, developing, and testing ideas that may lead to solutions' [13]; students' ability to conceive a plan for a particular purpose or effect [14]. Student designers' main objective of producing a design piece, which will result in any creative work, will involve the combination of how they use the available tools. However, the success of such an outcome will also have an indirect influence on how it is being engaged by the community of practice (involving studio activities, peer critiques at juries, software application, educators' feedback and comments inside and outside the studios and professionals influences outside the learning environment). The principles associated with design and instructors' interaction (educators acting as their instructors, group members, in situations of group works,) will contribute to the whole process of ideation since activity theory 'facilitates the consideration of interaction in social contexts which is a good starting point for studying contextually embedded practice' (Issroff \& Scanlon, 2002:79). Figure 2.11 is a diagram that gives a graphical presentation of the framework of the theory, as it relates to the study.

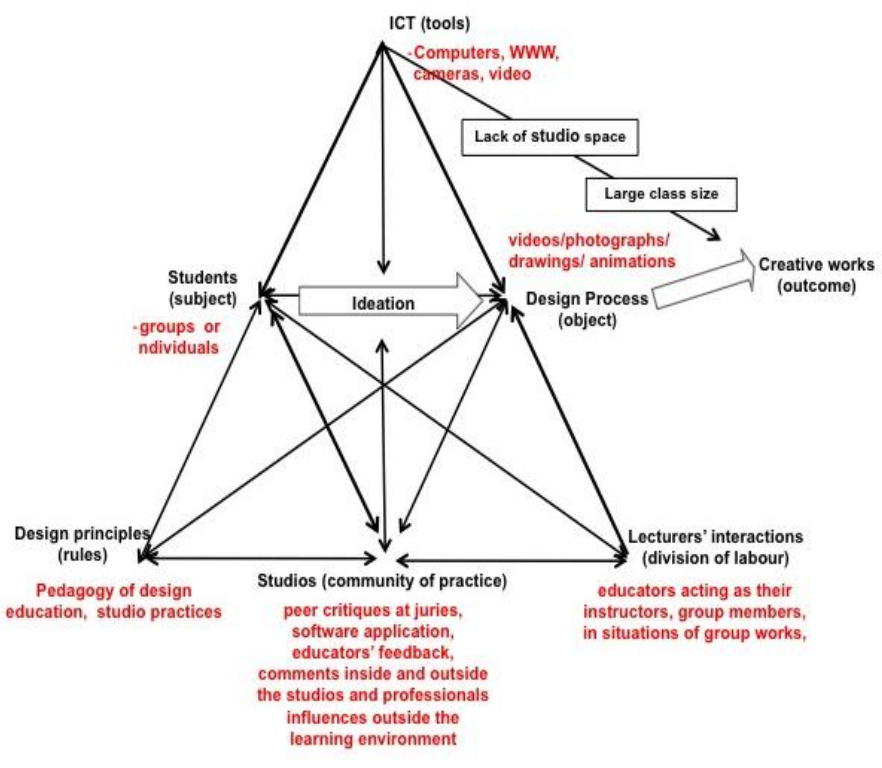

Figure 2: Framework of the theory as it relates to this study 


\section{METHODS}

With the qualitative methods of observation, artefacts, documents and interviews, the study presented was situated in a practical classroom setting in which students were given a project of branding a 'dying' telecommunication network provider 'Expresso' and also produce an advertising poster with the introduction of a new package for 'Expresso' customers. Students were to develop the ideas for discussions after which one will be chosen for final execution. The underlying principle is that students will develop their ideas using the pencil and their sketchbooks, before finally resorting to the computer for the final execution. The primary author observed the processes in which students engaged in their lecture room/studio environments. The focus was not the entire duration of the completed project; the emphasis was on the processes of developing ideas with tools, which dovetail to the final execution of the work. There was also the focus on the use of technological tools (computer and design software, Wacom tablets, the internet) against the traditional graphic design practice of idea development in the sketchbooks that led to the final presentation of the design.

The participants were final year graphic design students, numbering one hundred and twenty seven (127), and the rationale for using them was that they had undergone the basic fundamentals of ideation and had also done, at least six months' internship at professional design studios. They were also in transition to the professional world outside the university and therefore were neither novices nor fully professionals. Such a purposive sampling occurs when a researcher wants to identify particular types of cases for indepth investigation. The purpose is less to generalise to a larger population than it is to gain a deeper understanding of various types of cases [25]. There was only one lecture for this class.

Data was collected through note-taking and observation of the activities (both in the studio/lecture rooms), visual evidence of development (designs and thumbnail sketches), as well as conducting open-ended interviews with the participants. These were done to enhance the rigour and analysis of the qualitative empirical data gathered and also as a verification method for data triangulation [26]. As triangulation roles, these methods were also used as frame of mind - 'something that helps to keep your eyes and ears open for corroborating or conflicting ideas or data' ([26]).

\section{DISCUSSIONS AND ANALYSIS}

While the briefs were being discussed in the lecture rooms, students were seen scribbling thumbnail ideas in sketchbooks, with others also working on their laptops. It was interesting to observe how some students conceptualised ideas and try to brainstorm with computer technology to the blind side of the lecturer. Students were supposed to do such initial brainstorming using pencils and pens in sketchbooks. Those who captured ideas in the sketchbooks later were seen converting them digitally with Wacom tablets.
Interviewing students later on, it was revealed that conceptualization took place while the brief of the assignment were given and therefore needed to capture them before the idea fades off. Through sketches and visualisation, as a form of brainstorming, concepts were developed. These concepts formed the ideation activity that led to their objective and later resulted in the final outcome of the projects that were presented for juries. With this study, the steps were seen as more of professional approach than student's approach of the ideation process since the sketches were not in sequential order [27].

In the studio, students discussed their thumbnail sketches with their lecturer and colleagues, as a way of fine-tuning. Significantly, few of the students in the class were able to discuss their thumbnails sketches during formal studio jury. The major reason accounted for this was the large student population (127) against the limited time allocated for this course, though the assignment called for independent study. To facilitate this, students were asked to their initial thumbnails digitally and displayed via an LCD projector for the lecturer's comments during later studio discussions. These digital thumbnails began the digital process of ideation, where students tried out various layouts and different fonts and types on the computer to see how they work with the chosen concepts. From this point forward, the processes become exclusively computer-human interaction, with downloaded images - some taken from the Internet - alongside students' own photographs, taken at an attached photography studio with friends as models. It is important to note that these processes took between two to five days to arrive at the chosen solution to the problem.

The chosen ideas were then presented to the class as a final rough presentation of the concept for critique and jury in the studio. Students are required to make presentations and explain their outcomes for final approval and feedback upon completion of the idea generation phase. Except for a few cases, almost all presentations were accepted. At this stage the critique involved discussions on colour choice, layout and images that had been captured according to the brief requirements.

\subsection{Observation with activity theory: tools and activities}

Observing the processes from thumbnails to the final design (both initial and digital), and how students went through their ideation process identify that ICT inclusion created pedagogical challenges in the pedagogy of graphic design. Even though ideation is 'the process of generating, developing, and testing ideas that may lead to solutions' [13]), one engages with the mind more than tools in the process of brainstorming, organising, sketching, thinking and imagining with the view of creating ideas for implementation. From observation, about $70 \%$ of technological tools were used to realise these objectives and outcomes during the ideation process by students. These included the computer technology, the Wacom tablets, scanners and software for sketches, 
drawings and also for refining the images, which were mainly for the ideation process. Students used appropriate software to sketch and fine-tuned their sketches, leading to further conceptualisations for the brainstorms in the ideation process.

Most students had used the pencils and sketchbook for the initial capturing of briefs and conceptualisation but along the line, switch to the use of ICT tools, and end up finishing the work with ICT. The pedagogy of design education calls for more interactions since the lecturer acts as the 'client' and 'master', according to the Bauhaus principle. This principle informs the basis of graphic design pedagogy, especially in the developing countries. However, this interaction is hardly seen at the developing stages and the only interaction student had with lecturers was when the briefs were discussed in the studio/lecture rooms. This is in contrast with the Bauhaus principles and thus creates a contradiction (Figure 6, A1) where there was suppose to be teachers' interactions with students.

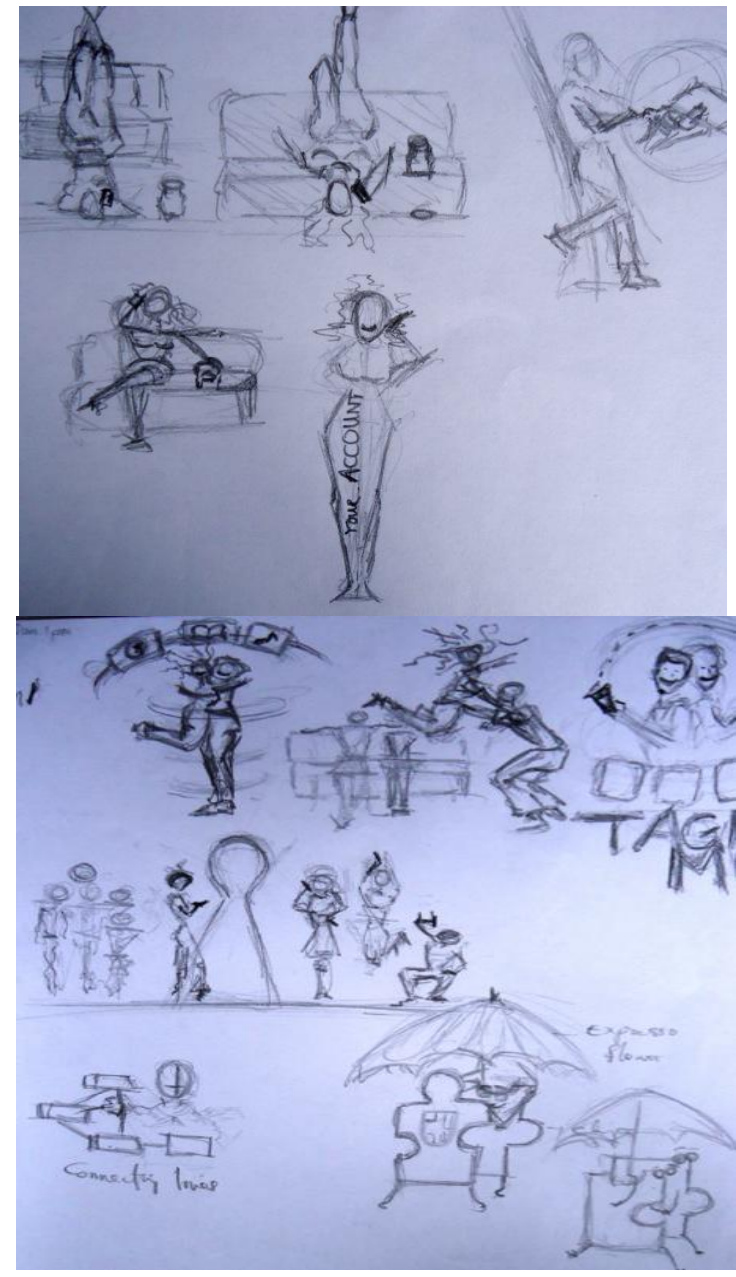

Figure 3: Samples of thumbnail sketches by students captured digitally for fine-tuning

During studio interaction, especially juries and with students, no meaningful feedback was captured since the large class did not allow for proper interactions (A2, Figure 5). Students whose works were displayed on the projector had one or two feedbacks from peers, as the majority of their peers were far from the displayed works and were therefore seen concentrating on their own works in their sketchbooks. As Graham [28] emphasised, 'criticism is the main pedagogical method used in the design studio'. The studio revolves around teachers' demonstrations, desk critiquing given to individual students by peer and teacher, and juries of final design solutions. 'Critiques in the studio also help students develop their own critical faculties by instilling the process of reflecting and reacting to design intentions, which lead to their design decisions, and then reacting to the consequences of each action' [28]. In this reported study, there were not enough critiques and interactions that helped the individual students in their design decisions. Moreover, there was no pedagogy to integrate ICT, which will allow such jury to be conducted and thus resulting in serious contradictions (A2). It might be significant to note that within the students, they have study groups and when they meet, some aspects of 'critiquing' go on among themselves (A3).

Even though some ideas were easily captured with the pencil on paper while others were captured digitally, the quantity of sketches did not reflect the pedagogy of design as indicated by Hodge [29]. Moreover, the final design solutions also did not reflect in the less number of thumbnails seen from the sketches, even though the designs indicated 'great' ideas from the brief. Later in an interview, one such student indicated that 'an idea can creep up at the final stages of all your thumbnails, and the more you come up with them the more new ideas you can come up with'. Such activity could create problems with pedagogy since ideation requires a follow through of sketches to arrive at the design solution. Traditionally, the designer's way of thought has to go through the design process to communicate effectively - problem identification, brainstorming/thumbnail sketches, roughs, finished rough/comprehensive, and the final design - will have to be followed through according to the adopted rules (Fig. 4), [30]

Another significant 'disturbance' occurs in the pedagogy of graphic design (A6) when students are being 'forced' to go the traditional way of developing ideas without any clear pedagogy for ICT. As a result of large classes and lack of studio space students seem to circumvent the ideation process and arrive at their final outcome (A5), possibly due to absence of student/lecturer interaction (A1). For academic purposes, students have to include their thumbnail sketches when submitting their final works, and these should be hard copies. Careful observations of these sketches reveal that these sketches did not really follow through the sequences and stages of the ideation process, creating contradictions of ideation in the activity (A4), even though the final designs clearly display great concepts and creative abilities of the students. Such situation also emphasised the argument that the emergence of digital studios has shifted the design process into the digital domain, and are allowing students to show their prowess in graphic design using ICT. 


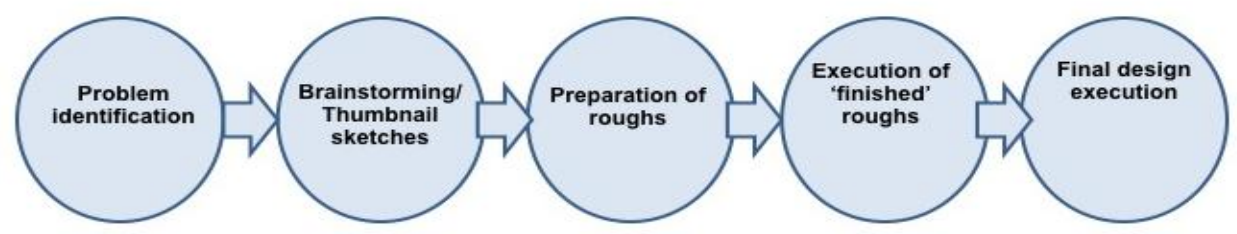

Figure. 4: The 'traditional method' of the design process[30]

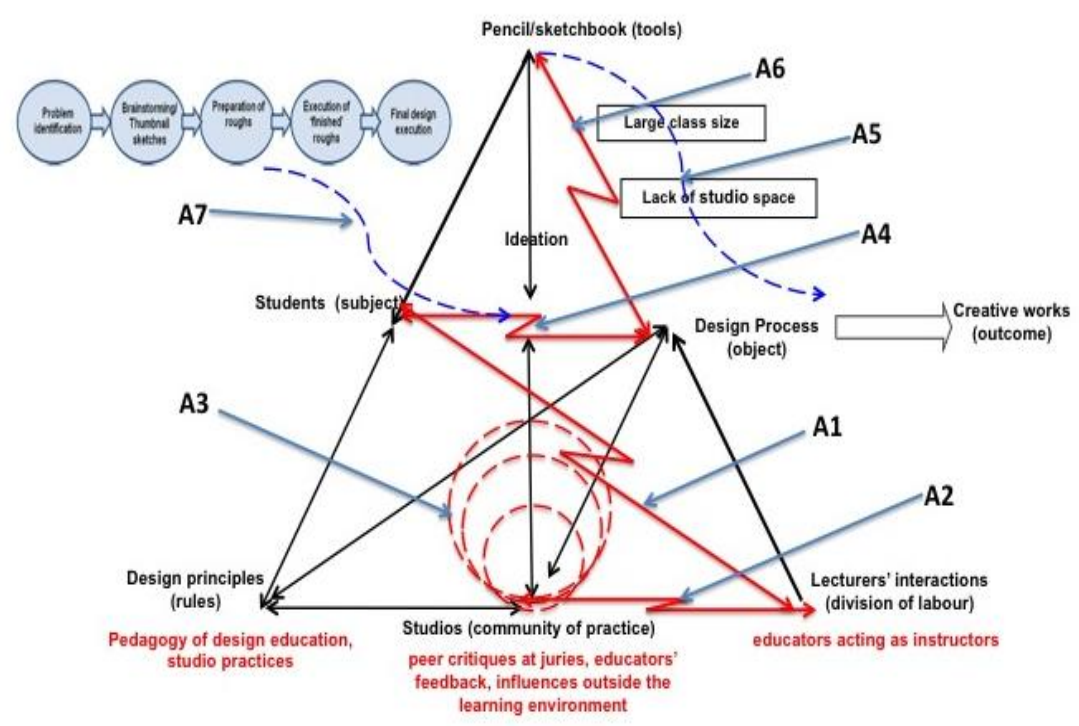

Figure. 5: The disturbances of the ideation process as captured in with the large class size and with ICT integration without the right pedagogy

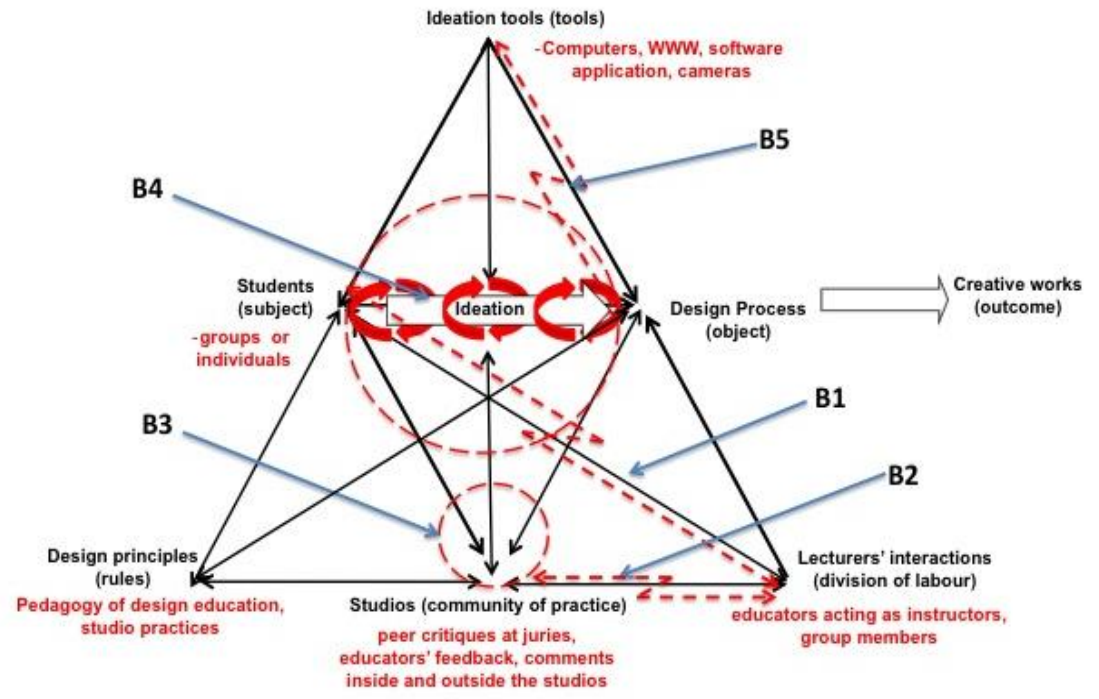

Figure. 6: The process of ideation with ICT integration and right pedagogy

\subsubsection{How do educators regulate the issue of ideation in graphic design with ICT?}

The introductions of ICT and computer technology have caused these tensions and contradictions because of lack of appropriate pedagogy for graphic design education. Many design educators are grappling with ICT and the influences which digital representation is having on the ideation phase of graphic design. Our study, focusing on activity theory, suggests the adoption of Innovation Education (IE) as a way of dealing with these issues. Thorsteinsson et al. [31] in their 
studies on Adoption of ICT in Supporting Ideation Skills in Conventional Classroom Settings makes a contribution of ICT in idea development, positing that ICT with ideation is possible digitally, through Virtual Reality Learning Environment (VRLE) technology. Our observations in the reported study reveal that IE was not part of the discourse of the project. With IE there is the possibility that one could use the VRLE tool for ideation in many course, including open and distance educational [31].

Though the class was large in terms of numbers, students could have engaged with lecturers online, using virtual design studios, in some discussions during which lecturers will communicate on their designs via emails and other social networks for feedbacks with clear pedagogy of ICT. Such a situation may require that both the student and lecturer have a clear understanding of the problems and sufficient specialised vocabulary with which to exchange ideas. In the virtual studio, since everyone will have the opportunity to view the sketches on display through online projections, others could make their contributions known, and feedback from other colleagues (members of the community of practice) will help shape ideas. These will then reduce the tensions and contradictions shown as B1, B2 and B3 in Fig 6

\subsubsection{What are the perceptions of ICT by design students in the current graphic design pedagogy?}

In the study, it was obvious students engaged with the Internet and other software applications to move their concepts and ideas into reality. Unfortunately, these could not be monitored since there was not pedagogy for such with ICT. Through IE and appropriate pedagogy, educators can monitor the ideation process during discussion and students ability to visit the 'web, to type in all the words like, 'lying', 'relaxing', 'stretching'; ... a word that has something to do with your composition" will be shaped. ICT will then be engaged as a tool, shaping the design process and the ideation process will however become evident as B4 (Fig 7). This is because students by trying out new types, layouts and manipulation of images on the computer, can go through vigorous ideation process based on iterative analysis - design, development, implementation and formative evaluation (ADDIE) - similar to the traditional method (Fig. 5). Such processes will also promote 'sense-making activity' as an ideation process for problem-solving [12].

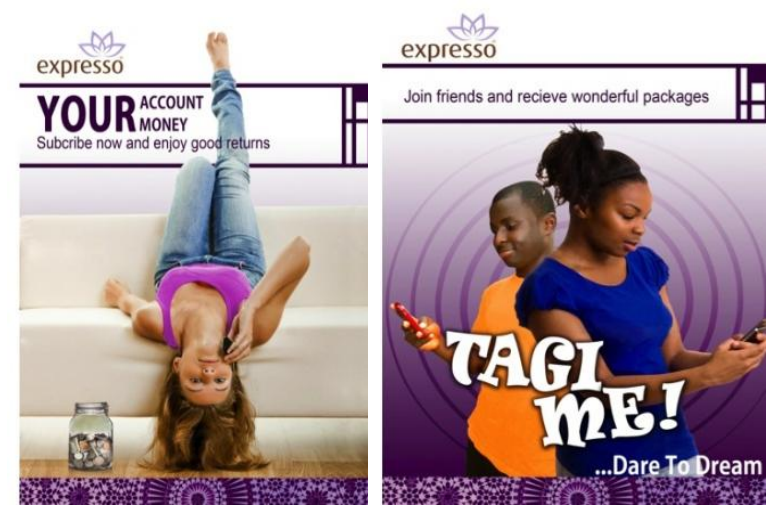

Fig. 7: Sample of 'refined' works with computer technology

A few years back, the term graphic design was linked to posters, billboards and printing only. Currently, graphic designers often work across a variety of disciplines and media. The scope of the profession in itself has been broadened, and is now use to describe a series of broad-based field of activity, encompassing design for print, advertising, moving graphics for film and TV and all manner of visual communication and design' [32]. Meggs and Purvis [33] believe the current graphic design field is much broader than in the past and now includes disciplines such as motion graphics, environmental commodities, and new media.

The nature of the profession today is such that one needs to always 'invent' some avenue to meet the challenges in its fast pacing transformation. According to Kowaltowski et al. [34], recent job market trends and the globalization of the design profession calls for higher design quality from design professionals.

The contemporary world with its dynamic
production of knowledge and speed in
technological advances, as well as obsolescence,
demands professionals capable of keeping up with
this pace... The new order also implies that design
students need a deeper understanding of
background knowledge and need to acquire new
abilities and attitudes towards design, with an
increased demand on creativity. Producing
designs that are fresh and new to the problem
domain are expected of our students and of design
professionals as a whole [34].

New abilities will require that graphic design students get the requisite skills and knowledge that will make them more competitive in the job market. Interviewing students revealed that their proficiency in the use of ICT would help them to become competitive in the job market. They will therefore learn and use available technology and software that will give them the leading edge in developing ideas for the design process. 
Students see ICT and the computer as augmenting the pace at which graphic design problems can be solved and permits designers to work more resourcefully. Such revolution means a lot in training student with the right skills to perform in such technological market. The profession now requires designers who can apply the right methodologies to solve the current design problems that include motions and interactive media. Exploration of the pedagogy of ideation is particularly critical to educational research where the object of its inquiry is not simply knowledge of ICT, but how ICT knowledge could be used in the ideation process. Such knowledge will be responsive to the current or emerging needs of practitioners and ultimately to the solution of professional and educational problems [35]. Moreover, research on the effects of ICT on learning are variable and inconclusive [36]. Perhaps educators and researchers need to focus on the issue that students need to be taught how to seek out new information for their designs, think critically and show initiative with the challenges of the fast-changing world of ICT. The era of digitization in the graphic design profession leads us to ask: what role is ICT playing in current graphic design studio when it comes to ideation?

\subsubsection{What are the purposes of ICT in the modern studio, and how do they feature in the ideation process?}

Two decades ago, the traditional studio concept was attacked in its 'hidden curriculum' by Ward [37]. Ward [37] problem was that the hidden curriculum, ran contrary to current educational processes and reinforce the 'hierarchical, topdown models of authority of most institutions, and inhibit truly independent thought' by students. He concluded by suggesting improving the quality of their professional services leading to a radical transformation of the design education system. Such transformation must address the issues of the hidden curriculum; include a process of increasing democratization of the studio context and content. The democratization of the studio context will mean allowing students the freedom to develop their own style of designing; by using tools students feel best in making their own meaning by learning from the results of their actions and inaction of the tools.

Since then many researches in design have come to emphasis the idea that design in the studio is not simply an act of doing, but one which requires a controlled conduct not base merely on an activity, but skills, and reasoning, which strips it from being merely an action, and thus takes it to another level where it is now considered as praxis [38][39][40]. In its context, structure, pedagogy and nature, the 'studio' has seen some transformation from the pre- $19^{\text {th }}$ century master/apprenticeship model influenced and is now experiencing digitally-oriented and virtual type in its professional and the educational settings ([42][43][8][41]).

In describing the studio in architectural design, Wallis et al (2010) paints a picture of the 'studio' typically as being central to the role of educating design students because it facilitates learning during the design process, encourages the integration of knowledge and skills, and generates an environment where professional norms and standards are cultivated [44]. Furthermore, it is important to acknowledge that the processes of designing and how to teach design are largely based on the profession's tacit knowledge and experiences. We are now experiencing $t$ virtual design studio (VDS) even though they come with its challenges, especially for the developing countries [8].

It seems to suggest that educators in the developing economies will now have to look at VDS as a way of reengaging our graphic design pedagogy in a way that will make useful the introduction of ICT in current curricula. But this also calls for reconsidering our teaching methods. Within the studio, learners' objectives could be directed and guided for effective execution of desired objectives through critiques, juries and outside professionals whose works act as inspirations to the learners [45][44]. They are also seen usually as problem-solving settings where educators who are experienced in the act of designing, tutor students individually or in groups, as per the Bauhaus model.

\section{CONCLUSION}

In conclusion, there seems to be lack of detailed investigation into what actually takes place in the ICT learning environment, most especially within the context of graphic design. Design educators will need to understand that ICT does not exist in isolation; it is interwoven with the rest of the tools and participants in the learning environment. The purpose of ICT in the modern design studio, which now comprises technological innovations, will need to be clearly understood with regard to ideation process. Research into ICT-supported design education needs to shift attention towards the whole configuration of events, activities, content, and interpersonal processes. This issue becomes important since ideation is a fundamental and critical issue in design education and should be the focus not only in the traditional model of design process.

Pedagogically, graphic design should not be an exception to design education especially when it comes to ideation process in design. As technological developments are also taking place in the developing countries, there is the need for educators to take a look at what is happening in the educational world of design in the developing economies. Educators are eager to equip the schools with technology as a way of moving with modern times. But 'state-of-the-art building, fancy equipment, and bungling bureaucracies aside, teaching is about inspiring curious minds, recognizing raw talents, and challenging students to think beyond their perceived capabilities especially in the field of graphic design where the methods and products are interactive and constantly changing' [4]. Educators can only achieve this by developing a clearer pedagogy of ICT within ideation in the design process.

This study is a contribution to the quest for a clearer pedagogy, especially with regard to the developing economies. Furthermore, this article encourages us to develop 
an appropriate IE in our on-going research into issues that will greatly help in answering the question: what methods of ICT are there for the teaching and learning processes of ideation in graphic design and how effective are they for the educator and the learner in the developing economy? We believe this can be achieved within the right and appropriate framework for the research; an activity-oriented framework that relates to graphic design and that will eliminate completely, the tensions and imbalances in current pedagogy. It is hoped that these answers will eventually emerge as the study progresses.

\section{REFERENCES}

[1] Jonson, B. 2005. "Design ideation: the conceptual sketch in the digital age," Design Studies, vol. 26, no. 6, pp. 613-624.

[2] Stones, C and Cassidy, T. 2007. "Comparing synthesis strategies of novice graphic designers using digital and traditional design tools," Design Studies, vol. 28, pp. 5972 .

[3] Stones, C. and Cassidy, T. 2010. "Seeing and discovering: how do student designers reinterpret sketches and digital marks during graphic design ideation?," Design Studies, vol. 31, no. 5, pp. 439-460.

[4] Yeoh, K. C. 2006. "Recommendations for Design Educators and Students Who Embrace Computer Technology," International Journal of the Arts in Society, vol. 1, pp. $167-182$.

[5] Bender, D. M. 2005. "Developing a Collaborative Multidisciplinary Online Design Course," Journal of Educators Online, vol. 2, no. 2.

[6] Stensaker, B., Maassen, P., Borban, M., Oftebro, M., and Karseth, B. 2007. "Use , updating and integration of ICT in higher education: Linking purpose, people and pedagogy," Higher Education, vol. 54, pp. 417-433.

[7] Brown, T. H. 2008. "Beyond constructivism: Navigation in the knowledge era," On the Horizon, vol. 14, no. 3, pp. $1-14$.

[8] Kvan, T. 2001. "The pedagogy of virtual design studios," Automation in Construction, vol. 10, pp. 345353.

[9] Bennett, R. 2000. "The omnium project: proposing a framework for creative online interaction," The omnium project: Online.

[10] Bender D. M. and Vredevoogd, J. D. 2006. "Using Online Education Technologies to Support Studio Instruction," Educational Technology \& Society, vol. 9, no. 4, pp. 114-122.

[11] Ranjan, M. P. 2005. "Creating the Unknowable: Designing the Future in Education," Ahmedabad.

[12] Kimbell, R. 2004. "Ideas and Ideation," Journal of Design and Technology Education, vol. 9, no. 3, pp. 136-137, 2004.

[13] Brown, T. 2008. "Design Thinking," Harvard Business Review, no. June, pp. 84-95.

[14] Yeoh, K. C. 2002. "A study on the influences of computer usage on idea formation in graphic design students," Texas Tech University.
[15] Dorst K. and Cross, N. 2001. "Creativity in the design process: co-evolution of problem-solution," Design Studies, vol. 22, no. 5, pp. $425-437$.

[16] Cross, N. 1997. "Creativity in design: analysing and modelling the creative leap," LEONARDO, vol. 30, no. 4, pp. $311-317$.

[17] Schenk, P. 1991. "The role of drawing in the graphic design process," Design Studies, vol. 12, no. 3, pp. 168181.

[18] Schenk, P. 2007. "Developing a taxonomy on drawing for design," in International Association of Societies of Design Research, pp. 1-15.

[19] Tan, S. and Melles, G. 2010. "An activity theory focused case study of graphic designers' tool-mediated activities during the conceptual design phase," Design Studies, vol. 31 , no. 5, pp. 461-478.

[20] Sagun, A., Demirkan, H., and Goktepe, M. 2001. "A Framework for the Design Studio in Web-Based Education," JADE, vol. 20, no. 3, pp. 332-342.

[21] Issroff, K. and Scanlon, E., 2002. "Using technology in Higher Education: an Activity Theory perspective," Journal of Computer Assisted Learning, vol. 18, pp. 7783.

[22] Jonassen, D. H. and Ronrer-Murphy, L., 1999. "Activity Theory as a Framework for Designing Constructivist Learning Environments," Educational Technology Research \& Development, vol. 47, no. I, pp. 61-79.

[23] Nardi, B. 1996. Context and consciousness: activity theory and human-computer interaction. Mass: MIT Press.

[24] Engeström, Y. 1999. "Activity theory and individual and social transformation," in Perspective on activity theory, Y. Engestrom, R. Miettinen, and R.-L. Punamaki, Eds. Cambridge: Cambridge University Press, pp. $19-38$.

[25] Neuman, L. W. 2007. Basics of Social Research: Qualitative and Quantitative Approaches, Second. New York: Pearson Educational, Inc, p. 365.

[26] Yin, R. K. 2011. Qualitatively Research from start to finish. New York: The Guilford Press, p. 369.

[27] Resnick, E. 2003. Design for communication: Conceptual graphic design basics. New Jersey: John Wiley and Sons.

[28] Graham, E. M. 2003. "Studio design critique: student and faculty expectations and reality," Louisiana State University.

[29] Hodge, S. N.D. "Drawing," 2009. [Online]. Available: http://psd.tutsplus.com. [Accessed: 20-Apr-2009].

[30] Appiah, E. and Cronjé, J. 2011. “Thumbnail sketches on idea development: the drawing board vs computergeneration," in Design, Development and Research (DDR): Annual Research Conference of the Faculty of Informatics and Design, Cape Peninsula University of Technology ISBN 978-0-620-52128-4, pp. 94-103.

[31] Thorsteinsson, G., Page, T., and Niculescu, A. 2010. "Adoption of ICT in Supporting Ideation Skills in Conventional Classroom Settings," Informatics and Control, vol. 19, no. 3, pp. 309-318. 
[32] Mcquiston, L. 1998. Graphic agitation: social and political graphics since the sixties, 1st ed. London: Phaidon.

[33] Meggs P. and Purvis, A. W. 2012. Meggs History of Graphic design, 5th Editio. Hoboken, New Jersey: John Wiley and Sons Inc,

[34] Kowaltowski, D. C. C. K., Bianchi, G., and Paiva, V. T. 2010. "Methods that may stimulate creativity and their use in architectural design education," International Journal of Technical Design Education, vol. 20, pp. 453476.

[35] Kozma, R. 1991. "The Relationship Between Technology and Design in Educational Technology Research and Development: A Reply to Richey," Russell The Journal Of The Bertrand Russell Archives, pp. 1921.

[36] Ungerleider, C. S. and Burns, T. C. 2002. "Information and Communication Technologies in Elementary and Secondary Education: A State of the Art Review," Montreal.

[37] Ward, A. 1990. "Ideology, culture and the design studio," Design Studies, vol. 11, no. 1, pp. 10-16.

[38] Öztürk, M. N. and Türkkan, E. E. 2006. "The Design Studio as Teaching / Learning Medium - A ProcessBased Approach," Journal of Art and Design Education, vol. 1, no. 2006, pp. 96-105.

[39] Hasirci, D. and Demirkan, H. 2007. "Understanding the Effects of Cognition in Creative Decision Making: A
Creativity Model for Enhancing the Design Studio Process.," Creativity Research Journal ,, vol. 19, no. 2 , p. $259-271$.

[40] Uluog, B. 2000. "Design knowledge communicated in studio critiques," Design Studies, vol. 21, pp. 33-58, 2000 .

[41] Reffat, R. 2007. "Revitalizing architectural design studio teaching using ICT: Reflections on practical implementations," International Journal of Art and Design Education, vol. 3, no. 1, pp. 39-53.

[42] Kolarevic, B., Schmitt, G., Hirschberg, U., Kurmann, D. and Johnson, B. 1998. "Virtual Design Studio: Multiplying Time," Design, vol. 3, no. 1, pp. 2-9.

[43] Schnabel, M. A. and Kvan, T. 2000. "Implementing the first virtual environment design studio", University of Hong Kong.

[44] Wallis, L. Williams, T., and Ostwald, M. 2010. "The Studio ' conundrum: Making sense of the Australasian experience in Architectural Education," in International Conference on Design Education, July, pp. 1-5.

[45] Broadfoot, O. and Bennett, R. 2003. "Design Studios: Online? Comparing traditional face-to-face Design Studio education with modern internet-based design studios," in Apple University Consortium Academic and Developers Conference, pp. 1-13. 